\title{
The Erectile Dysfunction among Congolese Hypertensive Patients
}

\section{Stéphane Méo Ikama ${ }^{1}$, Odzebe-Anani Sévérin², Bernice Mesmer Nsitou ${ }^{1}$, Melvin Atipo-Ondongo², Jospin Makani'1, Thierry Raoul Gombet ${ }^{1}$, Suzy Gisèle Kimbally-Kaky ${ }^{1}$}

\author{
${ }^{1}$ Department of Cardiology, University Hospital Center of Brazzaville, Brazzaville, Congo \\ ${ }^{2}$ Department of Urology, University Hospital Center of Brazzaville, Brazzaville, Congo \\ Email: *stephane.mikama@gmail.com
}

How to cite this paper: Ikama, S.M., Sévérin, O.-A., Nsitou, B.M., Atipo-Ondongo, M., Makani, J., Gombet, T.R. and Kimbally-Kaky, S.G. (2018) The Erectile Dysfunction among Congolese Hypertensive Patients. World Journal of Cardiovascular Diseases, 8, 481-488. https://doi.org/10.4236/wjcd.2018.810047

Received: August 19, 2018

Accepted: October 26, 2018

Published: October 29, 2018

Copyright $\odot 2018$ by authors and Scientific Research Publishing Inc. This work is licensed under the Creative Commons Attribution International License (CC BY 4.0).

http://creativecommons.org/licenses/by/4.0/

\begin{abstract}
The authors conducted an analytical cross-sectional study over a period of 3 months among hypertensive patients, in order to determine the frequency of the erectile dysfunction (ED), and to identify the predictive factors. It included treated hypertensive patients, presenting an ED, defined as the incapacity to obtain or maintain an erection sufficient for satisfactory sexual activity. On 265 hypertensive patients, 172 (65\%) presented an ED. The average age was $58.2 \pm 9.7$ years. The associated cardiovascular risk factors were overweight/obesity in 99 cases (37.4\%), sedentariness in 90 cases (34\%), diabetes mellitus in 50 cases (19\%), dyslipidemia in 12 cases (4.5\%), and tobacco addiction in 6 cases (2.3\%). Arterial hypertension (HTN), old of $6.7 \pm 5.8$ years, was treated by bitherapy in 129 cases (48.7\%), and tritherapy in 102 cases (38.5\%). The principal therapeutic classes used were ACE inhibitors/ARBs in 213 cases (81\%), calcium antagonists in 205 cases (78\%), thiazides in 137 cases (52.1\%), and beta-blockers in 82 cases (31\%). ED, severe in 124 cases $(72 \%)$, and moderate in 48 cases $(28 \%)$, consisted of a difficulty to maintain the erection in 78 cases (45.3\%), to obtain the erection in 30 cases (17.4\%), and the two partners in 64 cases $(37.2 \%)$. In multivariate analysis, only the age, seniority of HTN, and the existence of diabetes mellitus were the predictive factors of ED. The early and effective assumption of responsibility of the AHT, as well as other cardiovascular risk factors whose diabetes, would make it possible to reduce the frequency of it, thus improving quality of life of the hypertensive patients.
\end{abstract}

\section{Keywords}

Arterial Hypertension, Erectile Dysfunction, Frequency, Predictive Factors, Congo 


\section{Introduction}

Arterial hypertension (HTN) is a major cardiovascular risk factor, and constitutes true public health problems in the world, concerning close to the $1 / 3$ of the population adult, and responsible for roughly 7.6 million annual deaths [1] [2]. Pathology with chronic evolution, it poses problems of the management to the long course because of the serious complications, and the side-effects of the antihypertensive drugs, with a negative impact on the adherence medication, and an increased risk of abandonment [3]. The association HTN and erectile dysfunction (ED) is frequent, and constitute a major concern for the experts, because of the deterioration of the quality of life of the patients [4] [5] [6]. In sub-Saharan Africa, few studies were brought back on the subject [7] [8]. In Congo, this preliminary study targeting at improving the management of the hypertensive patients aimed to determine the frequency of ED in the HTN, and to identify the predictive factors of ED.

\section{Patients and Methods}

It was about an analytical cross-sectional study with a prospective data collection, carried out in the unit of external consultations of the service of cardiology and internal medicine of the University Hospital of Brazzaville. It was held from May $1^{\text {st }}$ to July $31^{\text {st }}, 2015$ (either three months). It included a consecutive series of hypertensive patients known and treated, followed into ambulatory, presenting one ED, defined as the incapacity to obtain and/or maintain an erection effective for a satisfactory sexual activity. The score of the International Index on the Erectile Function (IIEF) [9] allowed evaluating the degree of severity of ED. For a normal value ranging between 25 - 21, ED was known as light between 20 16 , moderate between $15-10$, and severe between $10-5$. On the whole 265 patients were included. The variables of the study were:

- sociodemographic: frequency, age, matrimonial status and the standard statute of the union (unmarried, married, divorced, widowed, monogamist, polygamous), educational level (any, primary, secondary, superior), socioeconomic level (weak, average, high) according to ECOM [10];

- associated cardiovascular risk factors (diabetes mellitus, dyslipidemia, tobacco addiction, overweight/obesity, sedentariness);

- bound to the HTN: seniority, complications, therapeutic classes (angiotensin-converting enzyme inhibitors [ACEi], angiotensin receptor blockers [ARBs], calcium antagonists $[\mathrm{CA}]$, beta-blockers $[\mathrm{BB}]$, thiazides [Diu], spironolactone, centrally acting drugs, others) and antihypertensive protocols used;

- bound to ED: IIFE-5 score, nature of the disorder, starting factors, received treatments (phosphodiesterase-5 inhibitors [PDE-5i], intra-cavernous injection, herb tea).

The data were treated and analyzed with Epi-info 3.5.3 software. Chi-square and ANOVA tests allowed the comparison of the qualitative and quantitative variables. The research of the predictive factors of ED was done using a logistic 
regression. The significance level was $\mathrm{p}<0.05$.

\section{Results}

\subsection{Epidemiological Trends}

Of the 265 patients, 172 presented an $\mathrm{ED}$, that is to say, a frequency of $65 \%$. The median age of the patients was $58.2 \pm 9.7$ years (range: 33 and 83 years). They were monogamists in 188 cases (71\%), polygamous in 42 cases (15.8\%), and single people in 30 cases $(11.3 \%)$. The patients had a superior educational level in 162 cases (61.1\%), and an average socioeconomic level in 179 cases (67.7\%). The associated cardiovascular risk factors were overweight/obesity in 99 cases (37.4\%), sedentariness in 90 cases (34\%), diabetes mellitus in 50 cases (19\%), dyslipidemia in 12 cases (4.5\%), and tobacco addiction in six cases $(2.3 \%)$. The main characteristics of the study population are consigned in Table 1.

Table 1. Characteristics of the study population.

\begin{tabular}{|c|c|}
\hline & Patients $(\mathrm{N}=265)$ \\
\hline Mean age, years & $58.2 \pm 9.7(33-83)$ \\
\hline Seniority of hypertension, years & $6.7 \pm 5.8(1-30)$ \\
\hline Familial hypertension, $n(\%)$ & $183(69.3)$ \\
\hline \multicolumn{2}{|l|}{ Complications of hypertension, $n(\%)$} \\
\hline - any & $207(78)$ \\
\hline - heart failure & $23(8.7)$ \\
\hline - renal insufficiency & $15(5.7)$ \\
\hline - stroke & $15(5.7)$ \\
\hline - coronary artery disease & $5(2)$ \\
\hline \multicolumn{2}{|l|}{ Matrimonial status, $n(\%)$} \\
\hline - monogamist & $188(71)$ \\
\hline - polygamous & $42(15.7)$ \\
\hline - single people & $30(11.3)$ \\
\hline - widowed & $5(2)$ \\
\hline \multicolumn{2}{|l|}{ Educational level, $n(\%)$} \\
\hline - any & $3(1.1)$ \\
\hline - primary & $28(10.6)$ \\
\hline - secondary & $72(27.2)$ \\
\hline - superior & $162(61.1)$ \\
\hline \multicolumn{2}{|l|}{ Socioeconomic level, $n(\%)$} \\
\hline - weak & $70(26.5)$ \\
\hline - average & $179(67.5)$ \\
\hline - high & $16(6)$ \\
\hline \multicolumn{2}{|c|}{ Associated cardiovascular risk factors, $n(\%)$} \\
\hline - overweight/obesity & $99(37.1)$ \\
\hline - sedentariness & $90(34)$ \\
\hline - diabetes mellitus & $50(19)$ \\
\hline - dyslipidemia & $12(4.5)$ \\
\hline - tobacco addiction & $6(2.3)$ \\
\hline \multicolumn{2}{|l|}{ Antihypertensive protocol, $n(\%)$} \\
\hline - monotherapy & $18(6.8)$ \\
\hline - bitherapy & $129(48.7)$ \\
\hline - tritherapy & $102(38.5)$ \\
\hline - quadritherapy and more & $16(6)$ \\
\hline
\end{tabular}




\subsection{Antihypertensive Treatment}

The HTN, old of $6.7 \pm 5.8$ years, was treated by bi-therapy in 129 cases $(48.7 \%)$, tri-therapy in 102 cases (38.5\%), monotherapy in 18 cases (6.8\%), quadri-therapy and more in 16 cases (6\%). The principal therapeutic classes used were ACEi/ARBs in 213 cases (81\%), calcium antagonists in 205 cases $(78 \%)$, thiazides (Diu) in 137 cases (52.1\%), and beta-blockers in 82 cases (31\%). Associations ACEi/ARBs + CA and ACEi/ARBs + Diu were used, in respectively $41 \%$ and $27 \%$ of the cases.

\subsection{Erectile Dysfunction and Predictive Factors}

ED was lighter in 48 cases (28\%), moderate in 84 cases (48.8\%), and severe 40 cases (23.2\%). The disorder, of brutal installation in 20 cases (11.6\%) and progressive in 152 cases (88.4\%), consisted of a difficulty to maintain an erection in 78 cases (45.3\%), to obtain an erection in 30 cases (17.4\%), and mixed in 64 cases (37.2\%). The variability of the disorder was noted among 68 patients $(39.8 \%)$, and 103 patients $(60 \%)$ had lost spontaneous erections. The beginning of antihypertensive treatment, stress, marital problems, and financial problems were identified as factors starting of ED in respectively $23 \%, 22 \%, 8.2 \%$ and $7.6 \%$ of the cases. Concerning the treatment, 115 patients $(66.8 \%)$ had not received any treatment, 28 (16.2\%) an herb tea, $27(15.7 \%)$ a PDE-5 inhibitor, and $2(1.1 \%)$ an intra-cavernous injection. In bivariate analysis, it was not noted of a link between the antihypertensive drugs and $\mathrm{ED}$, in particular with the beta-blockers ( $\mathrm{p}$ $=0.44)$ and the thiazide diuretics $(\mathrm{p}=0.22)$. However, a link was noted between ED and diabetes mellitus ( $p=0.03)$, as well as sedentariness ( $p=0.02)$. In multivariate analysis, only the age $(p=0.0001)$, the seniority of $\operatorname{HTN}(p=0.0179)$, and the existence of a diabetes mellitus $(\mathrm{p}=0.0187)$ were observed as predictive factors of occurred of ED. Table 2 gives the results of the logistic regression.

\section{Discussion}

The erectile dysfunction (ED) is a frequent comorbidity during arterial hypertension (HTN), as noted in our study at more half of the patients, with various degrees of severity. In the literature, its prevalence is very variable, between 40

Table 2. Logistic regression of erectile dysfunction.

\begin{tabular}{ccc}
\hline Variables & OR (IC 95\%) & $\mathrm{p}$ \\
\hline Age (years) & $106(1.03-1.09)$ & 0.0001 \\
Seniority of hypertension (years) & $0.94(0.89-0.98)$ & 0.0179 \\
Complications of hypertension (yes/no) & $1.24(0.61-2.51)$ & 0.5529 \\
Diabetes mellitus (yes/no) & $2.65(1.17-5.98)$ & 0.0187 \\
Dyslipidemia (yes/no) & $1.0(0.26-3.92)$ & 0.989 \\
Sedentariness (yes/no) & $1.72(0.87-3.39)$ & 0.1178 \\
Overweight: obesity (yes/no) & $1.32(0.67-2.58)$ & 0.4137
\end{tabular}


and $90 \%$ according to the series, and it is higher among patients with cardiovascular risk factors (HTN, diabetes, obesity, dyslipidemia) or overt cardiovascular disease (coronary artery disease, heart failure, stroke) [11] [12] [13] [14] [15]. Indeed, during these cardiovascular pathologies, ED can, in some case, to pre-exist before occurred of the cardiovascular event, and others, to occur with the waning of the event, in varying proportions according to the nature of the event [16]. It was shown in this first case of the figure that the percentage occurred of cardiovascular events increased in a way proportional to the seniority of ED [16]. Concerning the HTN, it is known that the prevalence of being more important among hypertensive patients, a fortiori at those treated, compared to the none hypertensive subjects [17]-[24], and this whatever is the degree of severity [24]. Of psychogenic or organic origin, ED among hypertensive patients can be various mechanisms [15]. Indeed, if atherosclerosis, by the means of HTN and associated other risk factors seems to play a paramount role, the harmful effect of the antihypertensive agents is not to ignore [25] [26] [27] [28] [29]. Thus, among the antihypertensive drugs, it was shown that certain have a noxious role in occurred of $\mathrm{ED}$, such is the case of the centrally acting drugs, thiazides, spironolactone, and the old beta-blockers. On the other hand, other antihypertensive agents have a neutral effect (ACEi, calcium channel blocker) or even positive effects beneficial (ARBs, vasodilating beta-blockers such as the nebivolol) on the erectile function [30] [31]. In our series, it was not noted of the link between the antihypertensive drugs used and occurred of ED; relatively weak sample size and the short time of the study period can be the explanation about it. The progressive mode of installation of the disorder of erection, the loss of spontaneous erections, and the coexistence of other risk factors of atherosclerosis raised at the majority of our patients, plead for an organic origin. The advent of the PDE-5 inhibitors revolutionized the management of the patients suffering from ED, and the latter occupies a choice place in the algorithms proposed by the learned societies, like drugs of the first line in all types of ED [32] [33]. In addition to their beneficial effect on the improvement of the quality of life of the patients, this therapeutic class also contributes to improving medication adherence of antihypertensive drugs [34] and leaving a better blood pressure level control [35]. In our series, the still frequent recourse to the alternative treatments such as herb teas, and the weak use of the PDE- 5 inhibitors constitute an obstacle with the optimal management of the hypertensive patients suffering from ED in our context.

\section{Conclusion}

It comes out from this study that the erectile dysfunction is a frequent comorbidity among hypertensive patients. It is about a pathology little known, underestimated, and undertreated in this population, where arterial hypertension plays a paramount role in its occurred, but also certain antihypertensive drugs. The early tracking of, the effective management of arterial hypertension and as- 
sociated cardiovascular risk factors, the rational use of the PDE-5 inhibitors will contribute to improving to become to it patients; from where the need for a multi-field collaboration associating cardiologists and uro-andrologists.

\section{Conflicts of Interest}

The authors declare no conflicts of interest regarding the publication of this paper.

\section{References}

[1] Lawes, C.M., Vander Hoorn, S. and Rodgers, A. (2008) International Society of Hypertension: Global Burden of Blood-Pressure-Related Disease. Journal of Hypertension, 371, 1513-1518.

[2] Kearney, P.M., Whelton, M., Raynolds, K., Muntner, P., Whelton, P.K. and He, J. (2005) Global Burden of Hypertension: Analysis of Worldwide Data. The Lancet, 365, 217-223. https://doi.org/10.1016/S0140-6736(05)70151-3

[3] Mancia, G., Fagard, R., Narkiewicz, K., Redon, J., Zanchetti, A., et al. (2013) ESH/ESC Guidelines for the Management of Arterial Hypertension. Journal of Hypertension, 31, 1281-1357. https://doi.org/10.1097/01.hjh.0000431740.32696.cc

[4] Feldman, H.A., Goldstein, I., Hatzichristou, D.G., Krane, R.J. and McKinlay, J.B. (1994) Impotence and Its Medical and Psychosocial Correlates: Results of the Massachusetts Male Aging Study. The Journal of Urology, 151, 54-61. https://doi.org/10.1016/S0022-5347(17)34871-1

[5] Althof, S.E. (2002) Quality of Life and Erectile Dysfunction. Urology, 59, 803-810. https://doi.org/10.1016/S0090-4295(02)01606-0

[6] Manolis, A. and Doumas, M. (2008) Sexual Dysfunction: The "Prima Ballerina" of Hypertension-Related Quality-of-Life Complications. Journal of Hypertension, 26, 2074-2084. https://doi.org/10.1097/HJH.0b013e32830dd0c6

[7] Fall Diop, F., KA, O., Diallo, Y., Gaye, A., Sow, P.G. and Sylla, C. (2013) Profil épidémiologique des patients atteints de dysfonction érectile au centre de santé de Ouakam, Dakar-Sénégal. Med Afr Noire, 60, 449-458.

[8] Opadidjo, O.G. (2003) Male Erectile Dysfunction in Adult with Hypertension. The Role of Vascular and Cardiac Damage. Tropical Cardiology, 29, 3-7.

[9] Martin, M.A., Laumann, E.O., Fugl-Meyer, S., et al. (2004) Definitions, Classification and Epidemiology of Sexual Dysfunction. Health Publications, 5, 37-72.

[10] Deuxième enquête congolaise auprès des ménages pour le suivi et l'évaluation de la pauvreté (2011) Ministère du plan et de l'intégration. Vol. 1, Rapport du volet QUIBB-ECOM2, 142.

[11] Manolis, A. and Doumas, M. (2012) Antihypertensive Treatment and Sexual Dysfunction. Current Hypertension Reports, 14, 285-292. https://doi.org/10.1007/s11906-012-0276-5

[12] Manolis, A. and Doumas, M. (2009) Hypertension and Sexual Dysfunction. Archives of Medical Science, 5, S337-S350.

[13] Douma, S., Doumas, M., Tsakiris, A. and Zamboulis, C. (2007) Male and Female Sexual Dysfunction: Is Hypertension an Innocent Bystander or a Major Contributor? Rev Bras Hypertens, 14, 139-147.

[14] Doumas, M. and Douma, S. (2006) Sexual Dysfunction in Essential Hypertension: Myth or Reality? The Journal of Clinical Hypertension, 8, 269-274. 
https://doi.org/10.1111/j.1524-6175.2006.04708.x

[15] Vlachopoulos, C., Jackson, G., Stefanadis, C. and Montorsi, P. (2013) Erectile Dysfunction in the Cardiovascular Patient. European Heart Journal, 34, 2034-2046. https://doi.org/10.1093/eurheartj/eht112

[16] Thompson, I.M., Tangen, C.M., Goodman, P.J., Probstfield, J.L., Moinpour, C.M. and Coltman, C.A. (2005) Erectile Dysfunction and Subsequent Cardiovascular Disease. JAMA, 294, 2996-3002. https://doi.org/10.1001/jama.294.23.2996

[17] Johannes, C.B., Araujo, A.B., Feldman, H.A., et al. (2000) Incidence of Erectile Dysfunction in Men 40 to 69 Years Old: Longitudinal Results from the Massachusetts Male Aging Study. The Journal of Urology, 163, 460-463. https://doi.org/10.1016/S0022-5347(05)67900-1

[18] Rosen, R.C., Fischer, W.A., Eardley, I., et al. (2004) The Multinational Men's Attitudes to Life Events and Sexuality (MALES) Study: I. Prevalence of Erectile Dysfunction and Related Health Concerns in the General Population. Current Medical Research and Opinion, 20, 607-617. https://doi.org/10.1185/030079904125003467

[19] Riley, A.J., Steiner, J.A., Cooper, R., et al. (1967) The Prevalence of Sexual Dysfunction in Male and Female Hypertensive Patients. Journal of Sex \& Marital Therapy, 2, 131-138. https://doi.org/10.1080/02674658708407856

[20] Bulpitt, C.J., Dollery, C.T., Carne, S., et al. (1976) Changes in Symptoms in Hypertensive Patients after Referral to Hospital Clinic. British Heart Journal, 38, 121-128. https://doi.org/10.1136/hrt.38.2.121

[21] Bauer, G.E., Baker, J., Hunyor, S.N., et al. (1978) Side-Effects of Antihypertensive Treatment: A Placebo-Controlled Study. Clinical Science and Molecular Medicine, 4, 341s-344s.

[22] Croog, S.H., Levine, S., Sudilovsky, A., et al. (1988) Sexual Symptoms in Hypertensive Patients. A Clinical Trial of Antihypertensive Medications. Archives of Internal Medicine, 148, 788-794. https://doi.org/10.1001/archinte.1988.00380040028006

[23] Dusing, R. (2003) Effect of the Angiotensin II Antagonist Valsartan on Sexual Function in Hypertensive Men. Blood Pressure, 12, 29-34. https://doi.org/10.1080/08038020310021967

[24] Doumas, M., Tsakiris, A., Douma, S., Grigorakis, A., Papadopoulos, A., et al. (2006) Factors Affecting the Increased Prevalence of Erectile Dysfunction in Greek Hypertensive Compared to Normotensive Individuals. Journal of Andrology, 27, 469-477. https://doi.org/10.2164/jandrol.04191

[25] Manolis, A. and Doumas, M. (2016) Erectile Function in Cardiovascular Disease and Hypertension: The Role of Nebivolol. Journal of Hypertension, 5, 226.

https://doi.org/10.4172/2167-1095.1000226

[26] Viigimaa, M., Vlachopoulos, C., Lazaridis, A. and Doumas, M. (2014) Management of Erectile Dysfunction in Hypertension: Tips and Tricks. World Journal of Cardiology, 6, 908-915. https://doi.org/10.4330/wjc.v6.i9.908

[27] Doumas, M., Viigimaa, M. and Papademetriou, V. (2013) Combined Antihypertensive Therapy and Sexual Dysfunction: Terra Incognita. Cardiology, 125, 232-234. https://doi.org/10.1159/000351696

[28] Viigimaa, M., Lazaridis, A. and Doumas, M. (2012) Management of Sexual Dysfunction in Hypertensive Patients. Cardiology Clinical Practice, 4, 53-60.

[29] Viigimaa, M., Doumas, M., Vlachopoulos, C., Anyfanti, P., Wolf, J., et al. (2011) European Society of Hypertension Working Group on Sexual Dysfunction. Hypertension and Sexual Dysfunction: Time to Act. Journal of Hypertension, 29, 403-407. 
https://doi.org/10.1097/HJH.0b013e328342c659

[30] Manolis, A.J., Doumas, M., Viigimaa, M. and Narkiewitz, K. (2011) Hypertension and Sexual Dysfunction. European Society of Hypertension Scientific Newsletter: Update on Hypertension Management 32.

[31] Doumas, M. and Douma, S. (2006) The Effect of Antihypertensive Drugs on Erectile Function: A Proposed Management Algorithm. The Journal of Clinical Hypertension, 8, 359-364. https://doi.org/10.1111/j.1524-6175.2005.05285.x

[32] Hatzimouratidis, K. (2015) Reply to Pero Bokarica's Letter to the Editor Re: K. Hatzimouratidis, I. Eardley, F. Giuliano, I. Moncada, A. Salonia. Guidelines on Male Sexual Dysfunction: Erectile Dysfunction and Premature Ejaculation. European Association of Urology. European Urology, 68, e78.

https://doi.org/10.1016/j.eururo.2015.06.014

[33] Montague, D.K., Jarow, J.P., Broderick, G.A., Dmochowski, R.R., Heaton, J.P., et al. (2005) The Management of Erectile Dysfunction: An AUA Update. The Journal of Urology, 174, 230-239. https://doi.org/10.1097/01.ju.0000164463.19239.19

[34] McLaughlin, T., Harnett, J., Burhani, S. and Scott, B. (2005) Evaluation of Erectile Dysfunction Therapy in Patients Previously Nonadherent to Long-Term Medications: A Retrospective Analysis of Prescription Claims. American Journal of Therapeutics, 12, 605-611. https://doi.org/10.1097/01.mjt.0000181305.44330.4a

[35] Scranton, R.E., Lawler, E., Botteman, M., Chittamooru, S., Gagnon, D., et al. (2007) Effect of Treating Erectile Dysfunction on Management of Systolic Hypertension. American Journal of Cardiology, 100, 459-463. https://doi.org/10.1016/j.amjcard.2007.03.045 